\title{
Gamified approaches for Water Management Systems: an Overview
}

\author{
A. Castelletti ${ }^{I}$, A. Cominola ${ }^{I}$, A. Facchini ${ }^{3}$, M. Giuliani ${ }^{I}$, P. Fraternali ${ }^{I}$, S. Herrera ${ }^{I}$, M. Melenhorst $^{2}$, \\ I. Micheel ${ }^{2}$, J. Novak ${ }^{2,4}$, C. Pasini ${ }^{1}$, A.E. Rizzoli, ${ }^{3}$ C. Rottondi ${ }^{3}$ \\ ${ }^{1}$ Dept. Of Electronics, Information and Bioengineering, Politecnico di Milano, Italy \\ ${ }^{2}$ European Institute for Participatory Media, Berlin, Germany \\ ${ }^{3}$ IDSIA USI/SUPSI, Dalle Molle Institute for Artificial Intelligence, Switzerland \\ ${ }^{4}$ IACS-Institute for Applied Computer Science, University of Applied Sciences Stralsund, Germany
}

\section{Introduction}

Water demand is growing worldwide, especially in densely populated areas, as a consequence of population growth [1] and urbanization [2]. The spatial concentration of water demand in urban areas is impacting demand magnitude, peak intensity, share between use sectors, and indoor and outdoor usage [3]. This, coupled with climate change and land use change, is intensifying the stress on finite water resources, creating both operational and environmental challenges to water supply. To cope with this evolving context, traditional supply and management schemes need to be adapted to meet future demand whilst preventing unsustainable resources exploitation. In this context, keeping into account geographical constraints and increasing marginal cost often limiting capacity expansion through infrastructural interventions [4], demand-side management strategies are key to complement supply-side interventions for securing reliable water supply as well as reducing shortages and overall utilities' costs [5]. The potential of demand-side management interventions has been demonstrated in a number of works (see, for a review, [6] and references therein), especially in the last two decades, fostered by the promotion of several water saving programs worldwide, particularly in areas affected by prolonged droughts (e.g., California [7]) or low-recharge periods (e.g., Australia [5]).

Within the broad portfolio of demand-side management interventions that can be implemented (i.e., technological, financial, legislative, maintenance, and educational), many recent works (e.g., [8] [9] [10] [11]) devoted attention to exploring the effect of behavioural change programs aiming at promoting water saving practices and increasing water awareness among users. Detailed investigation regarding behavioural interventions has been possible especially since the late 1990s, with the development of smart water meters [12], which enabled to monitor water consumption data with very high spatial (household) and temporal (from several minutes up to few seconds) sampling resolution [13]. Smart meters provide essential data to characterize the behavior of individual users and support the development of customized demand-side management interventions targeted on specific groups of users, and tailored to act on the drivers of their water consumption behavior. Indeed, a major role in forming the water demand is played by the behavior of water consumers, each potentially driven by diverse social and individual motivations and triggers. The achievement of an efficient water demand management depends on the aggregate effect of actions undertaken by several, diverse, individuals. This suggests that behavioural change programs built on customized demand-side management interventions can act on the specific drivers of users' demand and promote water and environmental friendly behaviors ( [14] [15]).

In this chapter, we focus on behavioural interventions and educational/awareness tools related to water issues to gamified approaches and persuasive technologies for water management, which aim at empowering users' knowledge and incentivize virtuous attitudes towards water conservation based on gaming mechanisms [16]. Computer and social sciences offer a wide set of gamified tools to build or raise environmental awareness in a variety of sectors (e.g., [17] [18]; [19]) and most recently also in the water domain. According to a recent review on serious games on environmental management [20], water management games constitute a relevant portion of the games belonging [1] to the more general category of serious games for environmental management (more than $20 \%$ of the 25 games considered in the study and developed between 1994 and 2013). These games represent promising tools both for learning purposes (game based learning), because they usually increase motivation and foster engagement, and for facilitating decision making processes, especially when a number of stakeholders with conflicting interests are involved, or validating behavioural models, such as agent-based models. Therefore, a variety of users, ranging from students and people involved in learning processes, to professionals, local stakeholders and decision makers can potentially benefit from the use of such tools. Yet, state-of-the-art literature often lacks exhaustive descriptions of some gamified ap- 
proaches to environmental and water problems, as well as quantitative measures enabling a fair assessment of the effectiveness of such tools for education and awareness purposes, or a comparison of different games under common criteria [20]. Our goal is therefore to review and critically analyze the most relevant research and industrial gamified approaches to water management, with a focus on water awareness and behavioural change. Additionally, we present some preliminary results in terms of user response and water conservation achievements obtained with the real-world application of a gamified approach.

The chapter is organized as follows. In the first part, we introduce some background notions on the enabling technologies for water management systems, i.e., smart metering infrastructures, big data analytics, and persuasive technologies. In Section 3, we review in detail some research and commercial gamified water management applications, especially developed within EU-funded projects belonging to the ICT4Water cluster. ${ }^{1}$ Finally, in Section 4, we present the gamified platform we developed as part of the EU-funded SmartH2O project [21], highlighting the current strengths and weaknesses identified during its application in two real world case studies, in Switzerland and in Spain.

\section{Technical concepts and methodologies}

Water utilities need support tools to match water demand with supply in a sustainable way. To this aim, it is first necessary to understand the factors than drive the demand by mining water consumption data collected at high frequency [3]. This is now possible thanks to the development of smart metering technologies and Internet of Things (IoT) protocols that support real time metering data collection, whereas cloud computing and big data infrastructures allow utilities to store and process meter data, and machine learning and pattern analysis enable the extraction of useful information such as identification of leakages and disaggregation of end-uses.

Water utilities deal with other important issues such as providing the consumers with educational materials on efficient water use, and designing adequate campaigns to influence their behavioral habits. Gamification and persuasive interfaces offer a viable solution to promote behavioral change, e.g. by providing consumers with visualization interfaces to increase their awareness on the amount of resources they use, and integrating incentives and gamified activities aimed at influencing their behavior towards more sustainable attitudes.

Finally, water utilities have to deal with fast changing policies, extreme weather effects and other factors that impact their revenues, therefore they require simulation tools to forecast the effects of different pricing policies and observe the expected reaction of the consumers: in this case machine learning techniques in combination with game theory can be applied to tackle the problem.

Therefore, in this section, we will provide basic notions on smart metering technologies, big data analytics for end use disaggregation and profiling, persuasive technologies such as visualization interfaces and gamification.

\subsection{Smart metering technologies}

Smart meters are electronic measurement devices installed at the users' premises to collect detailed household consumption data and provide them to the utilities for billing and monitoring purposes. Additionally, smart meters support bidirectional communications, thus enabling remote control and monitor of the overall performance of the grid and helping to detect failures and leaks [22] [23]. To do so, smart metering systems rely on a Local Area Network (LAN) to transmit individual consumption readings to a local data collector. This transmission can occur with different frequencies (e.g. daily or hourly), according to the capabilities of the meter and the specific usage of the collected data. The collector gathers the data and possibly operates some preprocessing. Data is then transmitted via a Wide Area Network (WAN) to the utility for processing and use by business applications.

22

${ }^{1}$ http://www.ict4water.eu/ 
On the customer side, one of the main benefits of smart metering is that it enables real-time or close to realtime consumption monitoring [24], which in turn raises the understanding and awareness of consumption and possibly leads to more efficient energy usage.

Furthermore, smart metering enables utility companies to offer better customer service by allowing for on demand readings, reductions of meter reading service costs, reductions of the response time to customer enquiries, more accurate billing, and reduction of the volume of non-revenue water losses thanks to a more accurate leaks detection [25]. Finally, by processing the huge amount of collected consumption data with statistical tools, companies are provided with a powerful tool for planning and forecasting the production and distribution of the resources based on real-time data.

Despite the benefits of smart metering systems, there are issues related to their implementation and perception that have hindered their adoption. One of the main concerns is privacy and security of the consumption data. Though secure design approaches have been applied to every component of the metering system, including level access control, data validation, and error checking as well as the encryption of data, the widespread usage of the utility backhaul communications and of public wireless networks has increased the exposure to potential security intrusions. Utilities are not only concerned about unauthorized access to user data, but also by potential unauthorized data manipulation to reduce billing [26].

Another issue is the meter accuracy: even though smart are very accurate and precise devices, individual meters are still prone to hardware/software failures. Therefore, utilities need to develop monitoring strategies and control the operational processes to identify anomalies and errors and correct them before the billing process is executed.

Finally, the biggest challenge is the initial roll-out time scale and cost of creating the smart metering infrastructure: the roll-out phase might take from month to years and should be managed with adequate planning strategies to minimize costs, technical and logistic issues [26]. There are also some hidden costs for the companies, e.g. the management of the infrastructure supporting the storage of big data, the acquisition or development of tools to perform analytics, and the adaption of the currently deployed system to enable the coexistence with the new infrastructure [27].

\subsection{Big data analytics for end use disaggregation and user profiling}

In recent years, the decreasing cost of storage media and the network bandwidth increase have made data storage and transmission relatively easy and inexpensive. This has pushed a number of companies from diverse business sectors to collect huge volumes of data and extract useful information to support their business by means of "big data" mining and analysis techniques. The term "big data" refers to enormous amounts of heterogeneous unstructured data produced at high bit-rate by a wide family of application scenarios [28], e.g. social networks, data streams from sensors, and scientific and enterprise applications. In turn, big data analytics are a set of knowledge discovery and data mining techniques adopted to uncover structures, trends, and patterns in big datasets. Such techniques are used for a wide range of applications, e.g. medicine, scientific research, computer performance enhancement, financial market prediction, insurance, marketing customer profiling, and resource optimization.

In the field of water management, big data and big data analytics are becoming more and more relevant since the advent of smart metering technologies [12] in the late 1990s, which made available new residential water consumption data at very high spatial (household) and temporal (from several minutes up to few seconds) resolution. Such data potentially contain detailed information about the behavior of individual consumers in terms of water consumption habits and water demand patterns, which can be employed for designing and evaluating alternative portfolios of consumer-tailored water demand management strategies. The need for automatic tools able to extract relevant information supporting the demand management out of large smart metered datasets has been fostering the development of data analytics techniques and mathematical models to accurately characterize sub-daily water consumption patterns, as well as end-use water consumption profiles.

As highlighted in a recent paper reviewing comprehensively several studies on high resolution residential water demand modelling and management [6], data analysis and modelling have a key role in uncovering water users' behavior, especially for the purposes of the so-called (i) automatic water end-use characteriza- 
tion and (ii) user modelling. More specifically, water end-use characterization consists in the disaggregation of the total water consumption, metered at the household level, into the different end-use categories (e.g., shower, toilet flush, irrigation, etc.). Automatic and scalable algorithms able to perform water end-use characterization are needed because the direct monitoring of end uses is not viable, as it would imply high costs for the installation of multiple sensors, as well as scarce acceptability by water users because of its intrusive nature. End use disaggregation is still and open research issue and several algorithms have been proposed in the literature [29]. Most of them consists of two main phases:

- Observation phase: the actual consumption of the appliances needs to be measured (in an intrusive way) during a given period in order to obtain reference consumption patterns of the single end uses, typically named as "signatures". This information is use to create the so-called "consumption base" or "baseline" and calibrate the end-use disaggregation algorithms.

- Classification phase: In this phase, machine learning techniques, usually based on optimization and pattern matching methods, are applied to breakdown the aggregate consumption data into single enduse contribution, after algorithm training. The most common algorithms use in disaggregation problems are decision trees, classifiers and clustering algorithms (for more information see [6] and references therein).

In turn, user modelling adopts data mining techniques to discover useful features in water consumption data to model heterogeneous water demand profiles at the household level, possibly as determined by natural and socio-psychographic factors, as well as by the users' response to different demand management interventions. More precisely, [6] suggests that user modelling includes two categories of models, i.e., descriptive and predictive models, whose goal is characterizing the patterns and trends of observed historical water demand time series, and forecasting future demands on the basis of natural (e.g., temperature and seasonality) and sociopsychographic determinants (i.e., variables characterizing user demography, as well as values, attitudes, interests, or lifestyles, such as age, number of house occupants, income level, conservation attitude, etc.), respectively. Data-driven techniques, multivariate and correlation analysis, data dimension reduction techniques (e.g. Principal Component Analysis [30]), as well as feature extraction and clustering methods are commonly used for the above purposes.Thus, as it traditionally happened mainly for a number of marketing purposes, the development of big data analytics techniques in the water sector is becoming fundamental to help understanding and characterizing the behavior of heterogeneous consumer, ultimately supporting the implementation of tailored demand management strategies and customized feedbacks supporting water conservation and management programs.

\subsection{Persuasive technologies}

Persuasive technologies attempt to change the user's attitudes or behaviors without coercion or deception [31] and find applications in visualization interfaces, video games, mobile devices and social media. We can find examples of persuasive technologies in online retail websites, health care, education, resource management, and collaboration tools. Persuasive applications aim at integrating within the habits of the user, and operate in a loop consisting of triggers, i.e., stimuli that alert the user and draw her attention, actions, which are the response of the user to a trigger, and variable rewards, which acknowledge the user's action in a way that surprises and stirs the desire to repeat the experience.

Using persuasive technologies provides some advantages over traditional media, or human persuaders. The most important is ubiquity: thanks to the proliferation of mobile and wearable devices, smart meters and home-devices interconnected by means of IoT technologies, people can be targeted at any place and at any time. The diversity of modalities is another important advantage: computers and electronic devices can deliver messages in a huge variety of modalities including text, audio, video, graphs, animations with a higher persuasion impact. Finally, computers can store and access huge amounts of information that enable them to present new facts, statistics and references as no other media can.

\subsubsection{Visualization Interfaces}

Visualization has recently become a popular topic in computer science: it is formally defined as the use of computer-supported, interactive, visual representations of abstract data to amplify cognition [32]. In other words, the visualization of information deals with the design and aesthetic aspects of computer interfaces to represent complex abstract data in a clear and comprehensible way, in order to enable users to analyze them 
with visual tools. Data visualization leverages technical backgrounds like information retrieval and data mining, computer graphics, and human-computer interaction.

Other interesting features of information visualization are the persuasion capabilities that it can have on user: it has been shown [33] [34] that a visual representation of some data can influence personal opinions about a topic by making people able to interpret the data, thus receiving feedbacks that showed them that their initial beliefs were wrong. Although ethical implications about the misuse of visualization to deceive or manipulate are currently under discussion, the persuasive capabilities of visualization can be positively used to influence users' behaviors.

\subsubsection{Gamification}

The concept of gamification has become increasingly popular in research and commercial applications. Gamification is defined as the use of game design elements in non-game contexts [35]. Some other terms like "serious games" and "games with a purpose" have also recently emerged. Although the two share many characteristics with gamification, they are fundamentally different: serious games are full functional games with a specific purpose like the education of a subject or the training on a skill, whereas gamified applications are enhancements of existing systems, services, tasks or processes, which incorporate game-based mechanisms but do not necessarily require them to function or be performed [36].

The main goals of gamification are the engagement of users and the enhancement of their experience, with the aim of increasing users' participation in the operations or social interaction aspects, or of raising users' productivity [37]. Gamification can also be used to set goals for the users in different contexts (e.g. teaching new skills): challenging users to meet an established requirement is known to be an effective motivational strategy [38].

In order to design a gamified application, it is important to characterize the people for which the game is intended and understand their motivations to play games. Bartle [39] proposed a player taxonomy based on the user motivations and interactions with the game and other players, which consists of four categories:

- Achievers: they are competitive and enjoy beating difficult challenges whether they are set by the game or by themselves. The more challenging the goal, the most rewarded they tend to feel. Most children like to see progress in terms of points, clearing a level or a similar sense of progression.

- Explorers: they like to explore the world, not just its geography but also the finer details of the game mechanics. They try to learn all the mechanics, short-cuts, tricks, and glitches that there are to know in the game, and they are more likely to play a game several time in order to do that.

- Socializers: they are often more interested in having relations with the other players than playing the game itself. The game is merely a tool they use to meet others in-game or outside of it or hang out with their friends.

- Killers: They are driven by competition with other people and prefer them over artificial intelligence controlled by the computer.

Figure 1 shows Bartle's players' taxonomy: the horizontal axis represents the preference of the user to interact with other players or the environment, the vertical axis emphasizes the preference of the user to act or interact with or on something. 


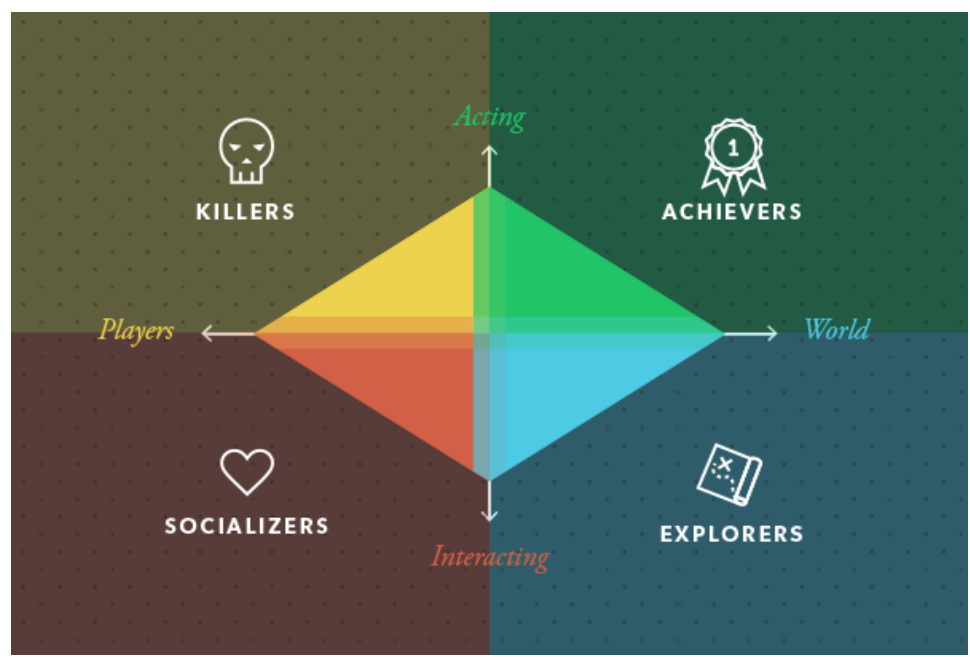

Figure 1: Bartle’s player taxonomy [40].

Based on the target type of player, the gamification designer can think about how to design the game mechanisms in order to engage the players. For example, when targeting an explorer the designer has to think about the size of the world and the diversity of geographies and interactions. Differently, if the target is the group of socializers, the focus should be on personalization features of the game and on the communication and cooperation systems.

There are four necessary elements to design a game. The first is the game mechanism that defines the procedures and rules of the game: the mechanics of a game describe the goal of the game, how to achieve it, and what happens when players do; choosing the mechanic defines the gameplay. There are several mechanisms that are widely used for gamifying everyday tasks [16]:

- Achievements and Badges: they are typically awarded if the player reaches a certain level oar mount of points in the game. They may require the user to perform tasks several times, master a skill or explore the environment.

- Progress Bar: it indicates how close a user has come towards the achievement given goal. When the player completes a task or an activity, the progress bar is filled to indicate the progress of getting closer to a goal. How much the progress bar is moved is often determined by the severity of a task or by using points. The progress bar may often be combined with experience points, where the experience points collected determines the movement of the progress bar.

- Experience Points: Experience points are an indicator of how much experience the player has gained within a game or setting. These points may be awarded by completing tasks, exploring areas and features or other similar activities. Experience points are usually combined with a leveling system, for example reaching certain amounts unlocks new levels, new rewards or new features. Experience points are also often combined with leaderboards.

- Leaderboards: they consist in lists of the players ordered by their collected points, completed activities or any other predefined metric. Each user has a score defined by rules set before a competition started, this score is compared to the one of the other players and players are ranked based on the scores. Leaderboards may be fully dynamic or state-based (i.e., a new order is recalculated after a certain period of time).

- Contests: they are categorized in duel-like head-to-head contests or free-for-all contests with no limit on the capacity of players. A duel-like contest may be a knockout style of competition where players compete to get the highest amount of points within a given time period or a similar type of a goal. In a free-for-all contest, the winner is whoever fulfills a specific goal to the best degree. The goal which players try to achieve is set be a specific set of rules determined before the start of the contest.

- Real-world Rewards: used together with leaderboards and contest, real-world awards may be given to some of the best players of the game. Usually the rewards are related with the topic of the application.

- Social networking: it provides to the users a common platform where they can share their achievement and recent activities, since users typically experience a sense of reward when their publications 
receive comments. It is possible to link the game to existing social networks like Facebook or twitter, or create specialize forums like Steam does in its platform.

The second element is the story, i.e. the sequences of events that happen during the game and the events that occurred prior to the start of the game. It could be a liner story or it can change depending on the user actions, therefore is linked to the game mechanics that should enable the storytelling.

The third element is the aesthetics, i.e. how the game should look like, the music and sound that go along with the story telling and the mechanics, aesthetic aspects constitute the most direct relationship with the user experience and influence engagement and immersion.

Finally, the fourth element that links them all together is the supporting technology: "it is essentially the medium in which the aesthetics take place, in which the mechanics will occur, and through which the story will be told." [16]. Choosing one technology enables you to do certain things but might make very difficult to perform some others, choosing it right is a complex topic.

\section{An overview on gamified water management systems}

We now overview the most relevant ongoing projects and applications aimed at the design and implementation of Water Management Systems and gamified applications in the context of resource efficiency and consumption awareness enhancement. Our aim is the identification of the key features and functionalities that such systems should offer to be adopted by water utility companies, as well as the design challenges and implementation approaches that are common to gamified applications.

\subsection{Urban Water Project}

Urban Water [41] is a project funded by the European Union's Seventh Framework Program for research and technological development, and it was developed by 12 partners from 8 different countries, among them there were three water utilities, one university, one video game development company and some governmental institutions.

The project was seeking to develop and test an intelligent water management platform for the efficient and integrated management of water resources in urban areas [42]. More in detail, the project aim was a $50 \%$ reduction of urban water waste over 5 years of operation. The platform provides tools to manage data coming from smart meters, process information to forecast water demand and water supply availability, detect leakages in the water supply network, support decision-making of water authorities and water distributors, and empower customers to reduce their water consumption.

The project objectives also included a market analysis at European level to identify market and legal European requirements and new market opportunities to ensure commercialization of the platform; the development of a new multi-technology communication gateway prototype combining wired and wireless technology, ensuring maximum geographic coverage and privacy; and the deployment of robust and proven data management tools based on Azure cloud platform guaranteeing efficient data management and customer confidentiality.

The project identified 7 enabling features to increase efficiency in water usage [43]:

- Effectively estimate water demand in urban areas in order to efficiently manage water supply chains.

- Reduce waste of water and economic losses associated to leakages in the urban water distribution network.

- Smooth daily water demand daily peaks in order to allow distributors to save costs related to the management of urban water distribution networks.

- Guarantee efficient and secure computational data management on the basis of smart grids' recent and upcoming deployments in Europe.

- Reduce operating and maintenance costs associated with water metering and billing in urban areas.

- Incentivize urban households to reduce their current consumption and soften the current European water demand peaks.

- Build effective partnerships and develop innovation synergies between equipment providers, ICT companies and water distributors. 
The platform consist on several components [44], the main one is the customer portal that offers consumption monitoring, consumption forecast, and billing access information. Besides this functionalities, the portal features a serious game "Water Mansion".

For the utility management, the platform provides a business dashboard (Figure 2) that shows the consumption (real and forecasted), the billing per hour and the notification of recent events; it provides access to other functionalities such as:

- the decision supporting tool that provide visual information about the water availability and demand predictions;

- the leakage detection system that allows night flow analysis and mass balance;

- hydraulic model building tools;

- the demand influence tools that include the automatic and dynamic billing address, the dynamic consumption analysis and the configuration options of the Water Mansion game;

- the integration tools that include the notification and alerts and management and monitoring.

The featured online serious game, Water Mansion [45], seeks to raise consumers' awareness about efficient water consumption and its relation with economic savings. In the game users should execute a series of task involving day-by-day actions, such as washing their hands, cleaning the dishes or filling the swimming pool. Each of this actions increases the consumption and reduces the "gold" that the user owns. The objective is to learn how to reduce consumption in order to save more "gold". The users are awarded a certain amount of "green drops" if in a period of time the consumption is reduced with respect to previous periods (Figure 3).

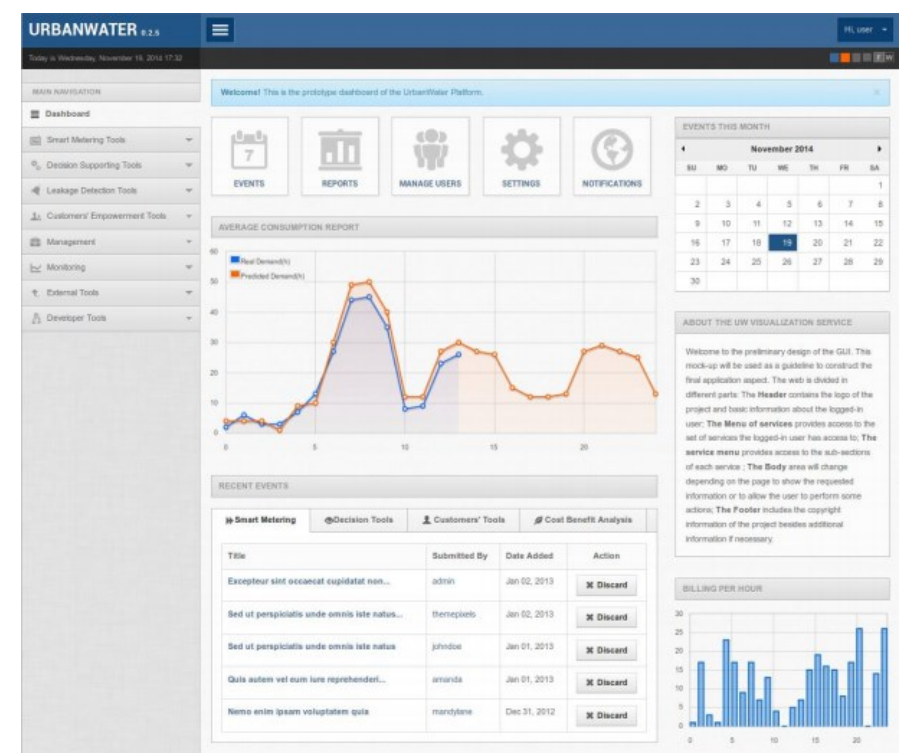

Figure 2: Urban Water Dashboard [44].

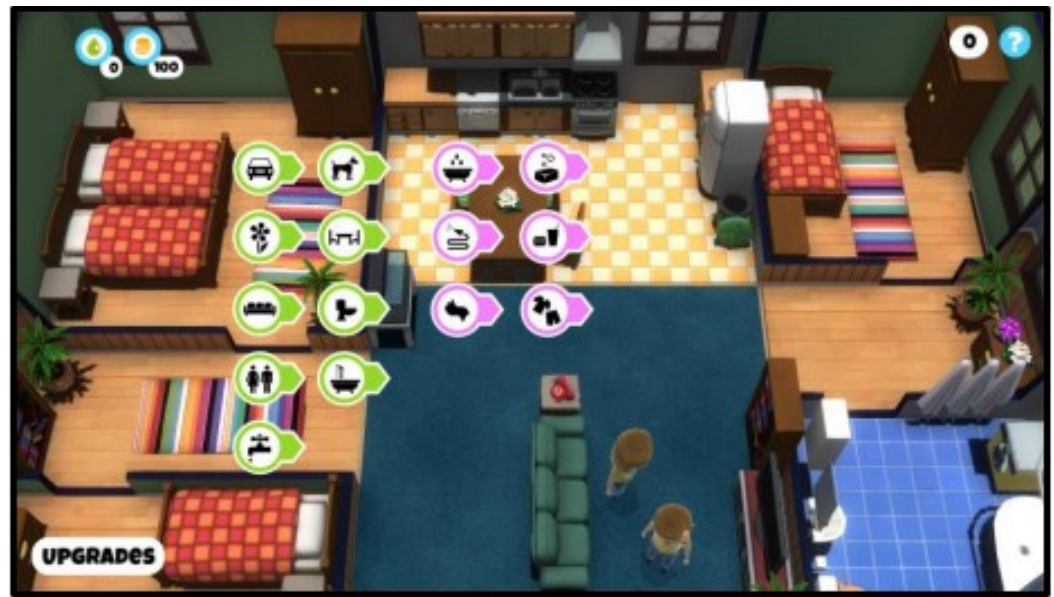

Figure 3: Water Mansion, on the top left: the green drop and gold scores; on the center: the action tags [45]. 


\subsection{WatERP project}

WatERP [46] is another project funded by the European Union's Seventh Framework Program. It was developed and supported by the Staffordshire University, the technological center of Catalonia and other 7 technological and governmental partners.

The project was focused on developing an "Open Management Platform" supported by real-time knowledge on the water supply and demand that enables an integrated and customized monitoring of the entire water supply distribution system, with the purpose of reducing the gap between water supply and demand through this information interaction and processing.

The project had two main objectives: an $8 \%$ water consumption reduction in water-scarce areas where water distribution is already efficient, and a 5\% energy usage reduction in areas where the water is abundant and the distribution is efficient but the consumption of energy is high. Additional goals were the increase of user awareness and the promotion of behavioral changes of water utilities and authorities, (not end-consumers).

From the technological point of view, the project aimed at identifying the key variables that must be monitored throughout the water supply distribution system to enable water supply and demand to be matched across the entire water supply network and while coping with water scarcity, drought and vulnerability indicators; and at developing protocols for real-time data collection and storage ensuring data quality, reliability and consistency.

The WatERP architecture consists of three main components:

- the data warehouse, which manages the processing and storing of consistent, continuous and usable water supply and usage data originating from heterogeneous sources (periodically or in real-time);

- the Decision Support System (DSS), which coordinates actions prioritizing water usage, improving distribution efficiency and reducing costs;

- the Demand Management System (DMS), which analyzes socio-economical drivers and policies to improve the management of water demand.

Information from the whole supply chain (including e.g. water sources and deposits, desalinization plants, distribution networks) are stored in the data warehouse, which makes it available to the users in real-time (with the possibility of personalizing data analytics) in order to support their decision making, policy making and water pricing, risk management and planning processes [47].

Demand forecasting is performed by leveraging advanced data analytics that calculate similarity indexes between the consumption pattern of the current day and historical consumption data available in the database, identify the most similar ones, calculate weights to be assigned to similar days, and finally output a prediction of the demand for the desired future date.

\subsection{Waternomics}

Waternomics [48] is an ongoing project developed collaboratively by 10 institutions, including the national university of Ireland Galway, the UNESCO-Institute for Water Education, and the municipality of Thermi, in Greece.

The goal of the project is to provide personalized and actionable information about water consumption and water availability to individual households, companies and cities in an intuitive and effective manner, at a time-scale relevant for decision making. Access to this information will increase end-user awareness and improve the quality of the decisions for decision makers in companies and in governments [49].

The project aims to accomplish these objectives by combining water usage-related information from various sources and domains to offer water information services to end-users, supporting personalized interaction with water information services, conducting knowledge transfer from energy management systems to water management systems, enabling sharing of water information services across communities of users, and enabling open business models and flexible pricing mechanisms responsive to both demand and climate/environmental conditions.

Additional project goals are the introduction of Water footprints (i.e., demand response and accountability) in the water sector; the interactive engagement of the consumers to enable efficient water consumption and behavioral change; the enactment of ICT-enabled water management by providing relevant tools and methodologies for water-related issues to corporate decision makers and municipal area managers.

The Waternomics platform consists of a four-layered architecture:

- the hardware layer includes by the smart meters installed at different levels of the water distribution network, depending on the location site, (e.g. at appliance level for households and at building level public buildings or offices). 
- The data layer stores, processes and analyzes the collected metering data to provide high level information reports (destined e.g. to municipalities).

- The support service layer implements the data analytics, the monitoring and alerting systems, and responds to the information requests from the application layer [50].

- The application layer is designed as an application portal: it provides basic functionalities (or applications) and can be extended by getting more applications from a marketplace. Users access the marketplace, select the application they are interested in based on their role and the activities they want to perform, and install it. This approach ensures great flexibility in terms of personalization [51] and makes the portal customizable for a wide range of user types and location sites: administrators can decide which application should be available for each role and existing applications can be enhanced by adding components. Third party applications can also be made available through an API [51].

The applications are divided in 4 categories:

- Monitoring: Applications that allow users to monitor their consumption and have it visualized.

- Learning: Applications that provide educational and informative material to users.

- Exploring: Applications that allow users to explore the potentials of the dataspace in terms of analytics and related services.

- Playing: Gaming applications or applications with gamification elements that help users to learn and educate themselves through playing or through interacting with each other in non-leisure contexts.

The platform provides also a set of independent components, also available through the marketplace, which enable the user to create custom applications by combining them (e.g. to create dashboards).

Some of the base applications for the household users are:

- Family Dashboard: Every family is entitled to create its own dashboard using a set of available components and choosing those that fit their needs. The total consumption component provides a visualization through a graph bar, the documentation explains that showing only cubic meters measurement might not be representative for most of the users, so it provides alternative representations like the number of kilograms of apples that could be produced with the same amount of water, or the amount of $\mathrm{CO}_{2}$ that was released in the environment to deliver that amount of water to the household, thus enhancing awareness of the family water consumption (Figure 4).

- Consumption timeline: This component emulates the function of a social media timeline by presenting series of events in a chronological order. The points along the timeline represent disaggregate consumption events and provide comparison with previous week's events of the same type (e.g., washing-machine water consumption).

- Notifications: the user can set notifications preferences for each type if events, and receive alerts accordingly. For example, the users can set an alert when the total consumption of the month is $10 \%$ higher than the one of the previous month.

- Drought conditions monitor: This application periodically receives data from the European Drought Observatory [EDO] and informs the users about drought periods, thus raising awareness of water scarcity.

For the administration side, the offered applications are:

- Management Dashboard: Managers are interested not only in monitoring the total consumption but also in controlling specific areas of the network. In the case of public buildings (e.g. an airport), it allows for monitoring specific building areas (e.g. the consumption of one of the terminals), as long as the metering infrastructure supports the collection of disaggregated data.

- Technician Dashboard: it provides overall information and notifications about critical detected events to support a timely on-field intervention from staff members.

- Leak Detection: the platform monitors the network and when a leakage is detected by the deployed sensors, the notification system sends alarms. Leakages can also be monitored through a graphical interface.

- Fault detection diagnostics: This application uses the baseline consumption and a series of rules to detect anomalies on the network flow, generating alerts about events that require validation or intervention. 


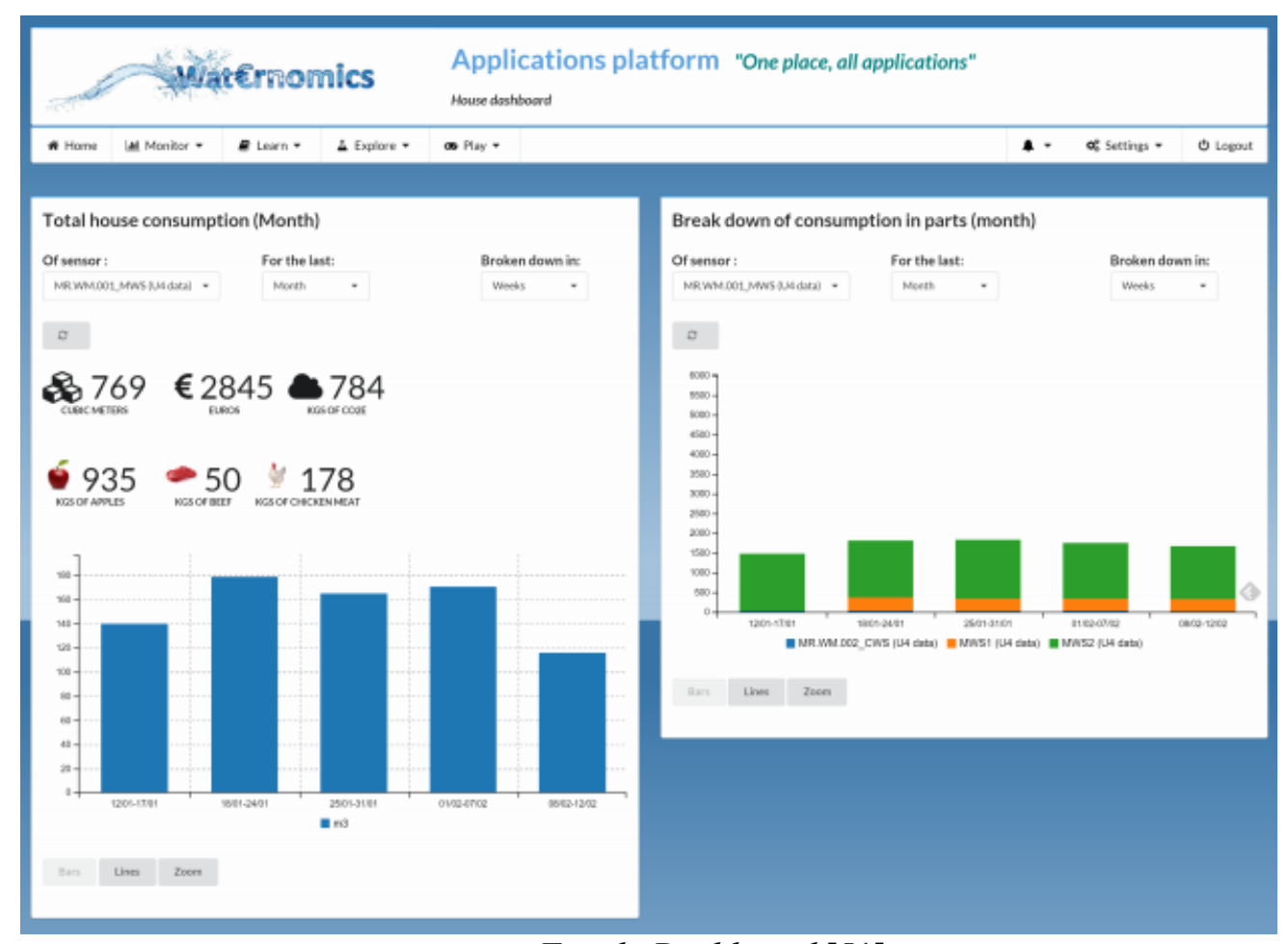

Figure 4. Family Dashboard [51].

For what concerns the game framework, the Waternomics platform [51] provides a leaderboard that shows the highest scores achieved by the users in the different game applications. The platform offers two games of trivia-like fashion. The first one is "Water Flavors": it asks the player to make educate guesses about how much water is necessary to produce certain products. In case of correct guess, the player is awarded with points. This way, the game aims at creating awareness by educating the player about the importance of water in the production of food and other products of common use. The information used in the game is retrieved from the Water Footprint Organization [52].

The second game is called "Water saving calculator" (Figure 5): in the first stage it provides a collection of water saving tips, in a second phase the player is asked to answer a set of questions by performing calculation based on the information provided by the tips. Players get points for the right answers and extra information for the wrong ones. The objective of the game is to make the players aware of the amount of water they are consuming and the potential savings that they can reach by changing some behaviors. As mention before, the architecture allows for the inclusion of additional games and gamified applications: the point storage and leaderboard management is achieved by an API. 


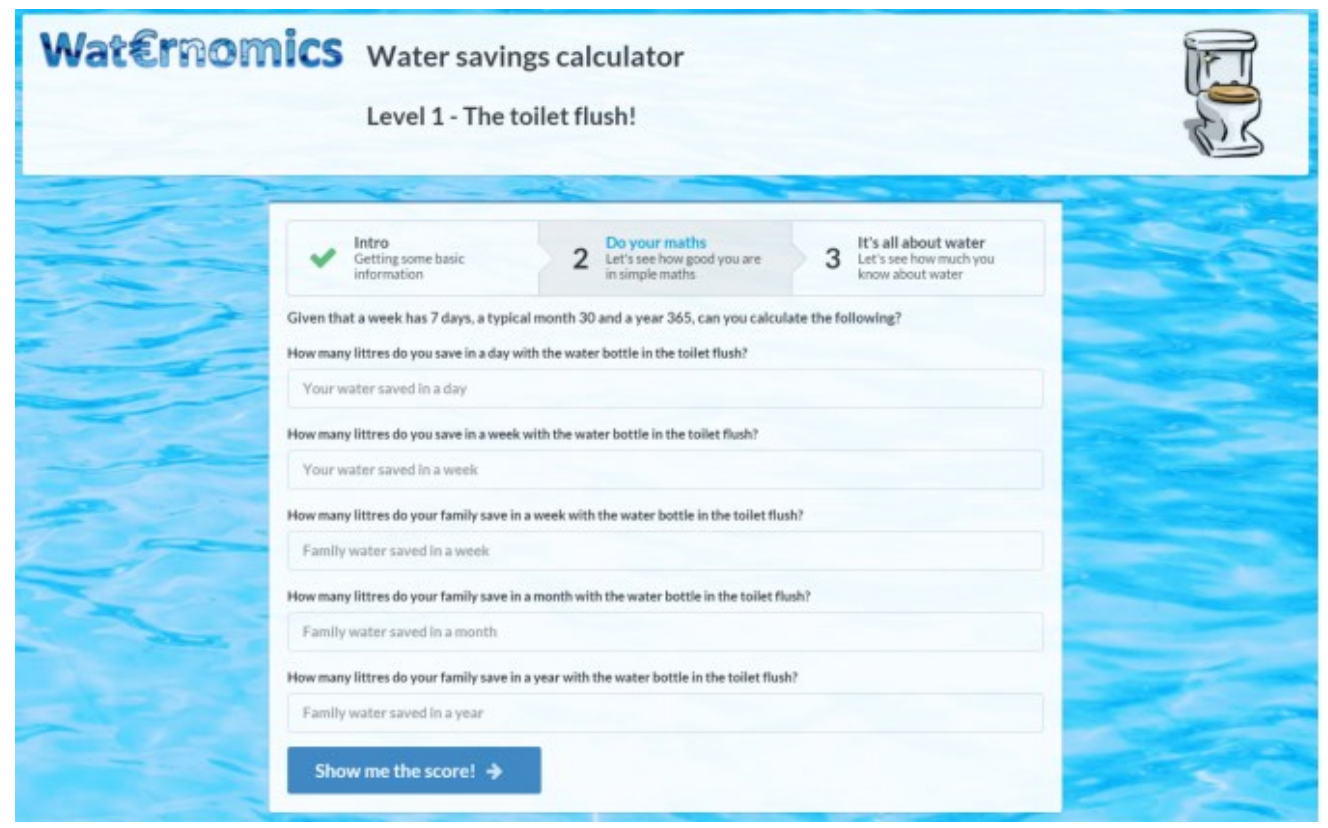

Figure 5: Water Savings Calculator [51].

\subsection{SmartH2O}

The SmartH2O project [53] is funded by the European Union's Seventh Framework Program for Research and Innovation. The project aims at creating a communication channel and a continuous feedback-loop between water users and utility companies, providing consumers with information on their consumption in near real-time while enabling water utilities to plan and implement strategies to reduce or reallocate water consumption. This can be achieved by exploiting collected information about how the consumers adapt their behavior as a reaction to different stimuli, such as awareness campaigns and changes in regulations or prices. To this aim, smart water meters are leveraged for collecting high frequency consumption data, which are used to provide high granularity information to water utilities on the state of the distribution network. At the same time, the collected information can be employed to stimulate a change in water consumption behavior. Accordingly, the SmartH2O system has been designed as a behavioural change support system (BCSS): "a socio-technical information system [...] designed to form, alter or reinforce attitudes, behaviours or an act of complying without using coercion or deception" [54]. The SmartH2O approach considers that a change in water consumption behaviour can occur when underlying psychological determinants change through a combination of different incentive and persuasion strategies, acknowledging that both in the energy domain and in the water domain consumption data alone are not sufficient to induce a sustainable behavioural change ( [15] [55]). Rather than relying on smart metered consumption feedback alone, the systematic approach followed by SmartH2O is grounded in motivational theory and research on incentive models, employing different mechanisms to incentivize users to save water. This has resulted in an ICT platform for improving consumer awareness, available on web and on mobile devices via a downloadable app. It incorporates smart metering, social computation, data visualization, big data analytics to model user behavior, and gamification to engage consumers in the process.

As inducing long term behavioral changes is a difficult task that involves psychological, social and cultural factors, the project incorporates a mix of multiple engagement strategies. All actions undertaken by the consumer, in all the different applications (web portal, mobile app and even an educational game) are logged. Based on such action logs and on the metered consumption data, a gamified social game is performed in which consumers are encouraged to save water through a mechanism that assigns points, badges and prizes based on the full spectrum of their actions; leaderboards and weekly/monthly competitions provide a social dimension to the game and increase engagement and motivation to participate by creating a sense of community. Moreover, through the game the users are encouraged to provide detailed profile information about their demographics and their household configuration: such data are greatly valued by utility companies, as their analysis can provide important insights on the factors that drive the demand trends. 
Figure 6 shows the home page of the Consumer Porta developed in SmartH2O. The page displays the histogram of the consumption readings collected with the smart meter infrastructure.
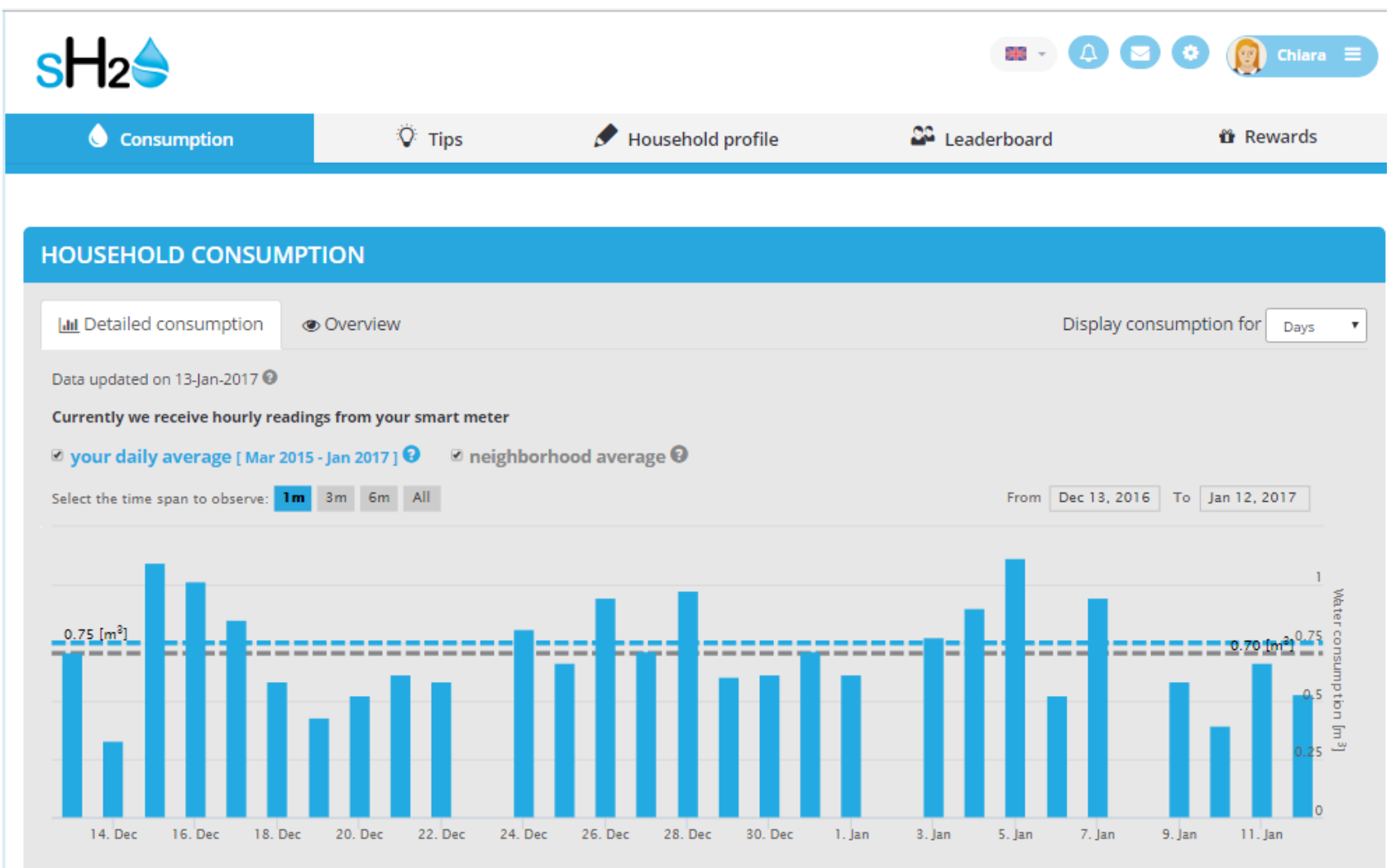

Figure 6: Home Page of the SmartH2O Consumer Portal

To improve the awareness of the impact of consumption and start engaging the user in a proactive water saving behavior, a complementary interface visualizes consumption data in an alternative way, shown in Figure 7.

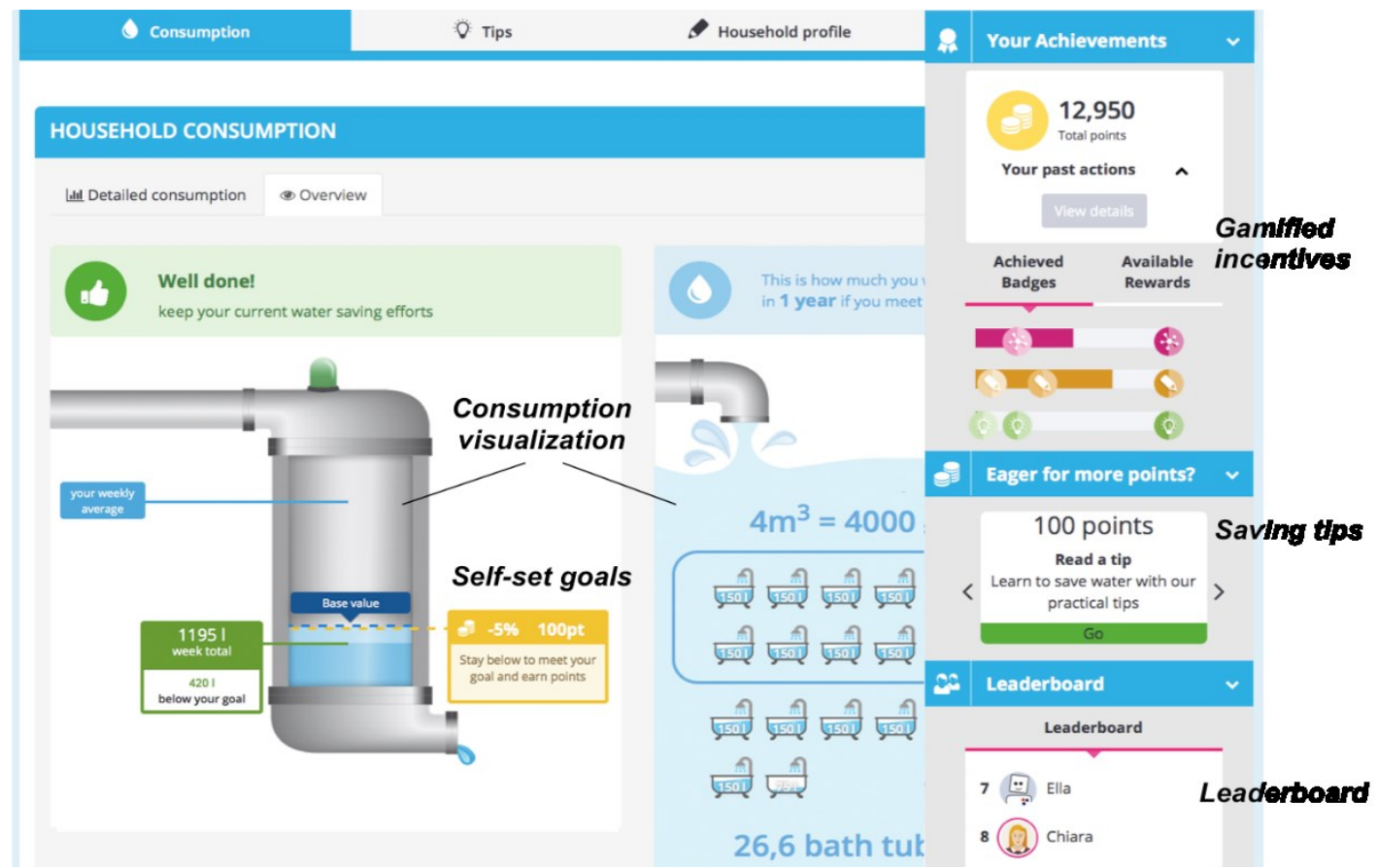

Figure 7: interface of the SmartH2O Consumer Portal showing an overview of the consumption progress 
In the overview visualization, the progress of the consumption in a certain period, e.g., the current week, is displayed as a tank filling with water. The tank metaphor is the basis for further incentive model elements, as discussed in more detail in Section 4.

As a complement to the utilitarian interfaces provided by the consumer web portal and mobile app, SmartH2O has also designed a water board game, called Drop! (show in Figure 8), with a digital extension, called Drop!TheQuestion.
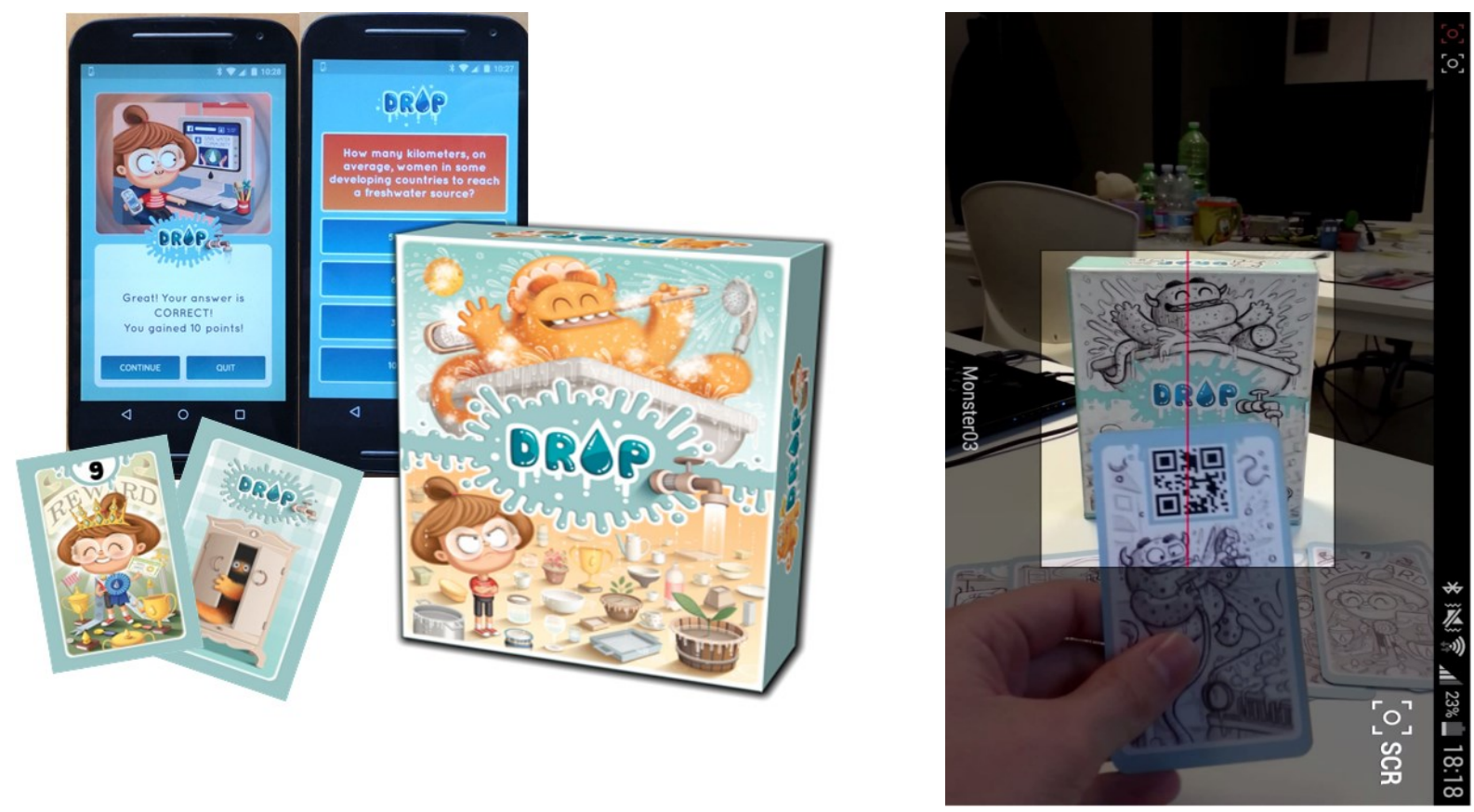

Figure 8: the Drop! board game and its digital extension (left); scanning a card with Drop!TheQuestion (right)

The Drop! board game is assigned as a reward to the users of the consumer web portal that achieve a minimum level of activity. It exploits a very popular home and family-oriented entertainment scheme, called "push your luck". In this class of games, the players repeat an action (e.g., drawing a card) until they decide to stop, due to an increased risk of losing points or the next turn (e.g., drawing a negative card). The Drop! board game is designed around the basic idea that a game does not need to be educational, to be... educational. The game metaphor is simple yet engaging: Lily is a young and clever girl who wants to save water. Lily's friend is a monster who does things in exactly the opposite way: the monster spills water (Figure 8). During the game, players do not need to answer questions or prove their knowledge to win, as is winning is determined by luck. The cards showing Lily are good cards and let the player score positive points, while the monster cards give players negative points. At the end of the game, players can transform the monster cards with negative points into positive points, by scanning a QR code on each monster card and answering a question received through their mobile phone or tablet (as shown in the right part of Figure 8). By playing the game within a household, saving water becomes a topic of conversation. This stimulates a water saving culture within the household, which in turn is a strong predictor of water consumption [56]. Playing the board game, and answering questions in the mobile app game increases knowledge. Users are incentivized to play the game in two distinct but related ways: the game design of the Drop! game itself, and the link with the gamified portal. Answering questions in the mobile game is awarded with points on the consumer portal.

The SmartH2O application is currently deployed in two real world scenarios: the first in Switzerland, the second in Spain. A more detailed description of the SmartH2O application and the case studies will be provided in Section 4. 


\subsection{A brief review of some commercial products}

With the growing concern for water scarcity and governments of developed countries starting to change their regulations and policies about water management, the market offers important business opportunities for big technology companies that have already started to work on resource management projects. In the following, we focus on two commercial platforms, respectively offered by IBM and Oracle.

IBM Intelligent Water [57] is part of the smart cities portfolio of the company: the platform offers situational awareness of operations at several levels and a range of advances tools. It does not necessarily replace the legacy systems of the utilities, but works on top of those by providing visualizations and data analytics, raising alerts, starting workflows to respond to a given situation, and displaying information on dashboards that can be configured based on the user role and access level (Figure 9).

Operational data are holistically leveraged to improve water management: the framework includes a water analytic component which aimed at reducing the non-revenue water through pressure optimization and pipe failure prediction; a monitoring component for smart meters to detect fraud; analytics components to improve irrigation, flood management and sewer overflows prevention.

The framework has been successfully deployed in three study cases. The first is located in China, where the platform was used to manage the operation of a hydropower plant in collaboration with SimuTech solutions [58]. The platform supported the whole management cycle, from the planning phase of the hydropower operations to the monitoring of the state of the reservoirs and of energy production.

A second study case is in Netherlands, where the national Ministry of Water adopts the platform to counteract the effects of extreme weather conditions, predict floods and droughts, and monitor the quality of drinking water, by exploiting its capabilities of proactively proposing preventive actions to possible issues.

Finally, the last study case is in Miami Dale County, where the tool is mainly used to monitor and detect leaks: using geospatial maps, the operators get alerted about potential problems that can be visualized through dashboards displaying various analytics.

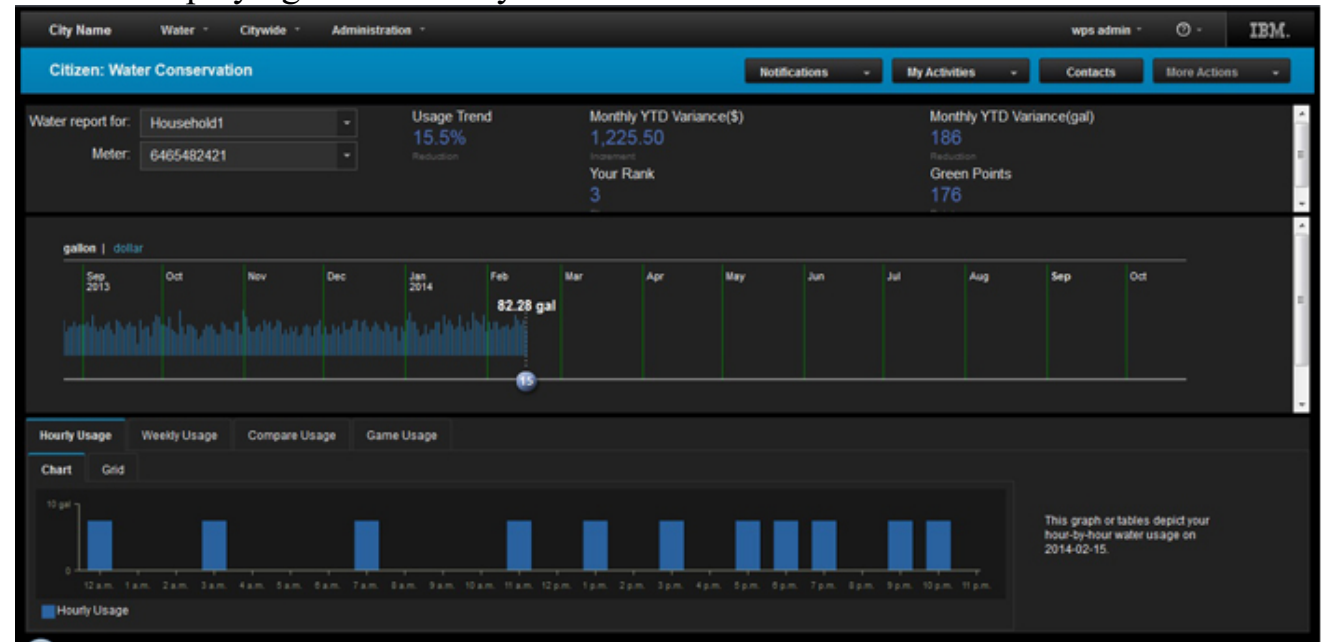

Figure 9: IBM Intelligent Water Dashboard, household level [Intelligent Water].

Oracle Utilities [59] offers a full suite of solutions for utilities, covering all aspects of management and planning. The suite is fully configurable to enable the utilities to adapt quickly to the changing regulations and ensures the full integration with legacy systems of the utilities.

Some of the most interesting resource management applications of the suite are:

- the metered data management component, which deals with consumption data validation for consistency and storage;

- the smart grid gateway, which operates as a data hub to ensure two way communication between the smart meters and the utility enterprise applications;

- the operational device management component, which provides asset management of the smart grid and meters and allows for real time configuration, automatic inventory, technical maintenance and security verification;

- the data raker, which provides advance data analytics, data visualization and enrichment including meter malfunction detection, customer tampering detection, establishment of maintenance priorities and billing exceptions detection; 
- the smart water network component, which provides automated valve operations management, leakage detection, outage isolation, shutdown management, and geo-spatial visualization for segment isolation.

Another group of applications of the suite supports mission-critical utility operations and include visualization applications that allows to access, view, digitally annotate and collaborate on assets information and case-related documents (schematics, blueprints, 3D models, etc.). They also provide pre-built dashboards, extractors and schemas for the information of the other products.

Finally, a set of complementary applications is designed for customer and billing support and dedicated to utilities serving residential, commercial, and industrial customers, with functions for managing payment and credit collection:

- The customer relationship management component support sales and marketing by segmenting the users in groups with similar characteristics and providing insight of the group's specific needs, besides handling customer order management.

- The rate management component handles pricing design and analysis, using analytics it evaluates the implications of the changes in prices offer to clients.

\subsection{Gamified Applications for resource efficiency}

Despite some successful studies, changing user's behavior via software is not an easy task. This is due to fundamental questions such as how to design an effective application to achieve the desired results and how to maintain behavioral changes in the long-term. As an example, the response-relax effect is often observed: after the change induced by the initial exposure to the persuasive technology, the attention paid to the feedback reduces and users revert to their previous behaviors [60].

Computer games have recently been advocated as a promising tool for computer-mediated behavioral change. They create an immersive environment that can attract also kids and teenagers to serious topics and manifest a high persuasive potential. Moreover, games effectively exploit the procedural representation approach, i.e., a form of symbolic expression that uses processes rather than language to convey 'how things work' [61]. In well-designed games, players can combine the processes embodied in the game and create new interactions beyond those considered by the game designers. This paradigm introduces new ways to persuade the player, which match well with the rhetoric concepts exposed by Fogg in [62] (triggers, motivation and ability) as the traditional means for persuasion through technology. Some recent contributions in environment and sustainability games focus on power conservation, environmental awareness, fossil energy use and water: Table 10-Table 11 compare some persuasive games specific for water management along their main distinctive features:

- Mechanics describes the type of the game.

- Roles list the roles assumed by the players.

- Players define the number of players that engage in a game round.

- Feedback specifies whether the game can interact with players during a round.

- Issues summarize the main problems highlighted by the game.

- Focus refers to the core persuasive/educational objective of the game.

- Target identifies a specific population of players targeted by the game.

- Data collection

- Platform specifies the technological environment/device for which the game is designed.

- Technology characterizes the implementation languages and frameworks.

Table 10: Summary of water games features. Games analyzed: Water wars [63], Atoll Game [64], Catchment Detox [65], FloodSim [66] and Aqua Republica [67].

\begin{tabular}{|c|c|c|c|c|c|}
\hline & Water Wars & Atoll Game & $\begin{array}{l}\text { The Basin Chal- } \\
\text { lenge/ Catchment } \\
\text { detox }\end{array}$ & FloodSim & Aqua Republica \\
\hline Mechanics & Turn based & $\begin{array}{l}\text { Rpg computer assist- } \\
\text { ed }\end{array}$ & Turn based & Turn based & Turn based \\
\hline Roles & Stakeholders & Family & Policymakers & $\begin{array}{l}\text { Flood policy strate- } \\
\text { gist }\end{array}$ & Mayor \\
\hline Feedback & Message & N/A & $\begin{array}{l}\text { Messages in game } \\
\text { and leaderboard }\end{array}$ & Messages in game & Messages in game \\
\hline Issues & $\begin{array}{l}\text { Policies, variable } \\
\text { weather conditions }\end{array}$ & $\begin{array}{l}\text { Policies, variable } \\
\text { weather conditions, } \\
\text { scarcity }\end{array}$ & $\begin{array}{l}\text { Policies, variable } \\
\text { weather conditions, } \\
\text { scarcity }\end{array}$ & floods & $\begin{array}{l}\text { Policies, variable } \\
\text { weather conditions }\end{array}$ \\
\hline
\end{tabular}




\begin{tabular}{|l|l|l|l|l|l|}
\hline Players & Multiplayer with chat & $\begin{array}{l}\text { Up to 16 presential } \\
\text { players }\end{array}$ & $1-2$ players & 1 player \\
\hline Focus & $\begin{array}{l}\text { Interaction among } \\
\text { inhabitants }\end{array}$ & $\begin{array}{l}\text { Land/water alloca- } \\
\text { tion conflicts }\end{array}$ & $\begin{array}{l}\text { Manage a river } \\
\text { catchment }\end{array}$ & $\begin{array}{l}\text { Raising awareness on } \\
\text { flooding policies }\end{array}$ & $\begin{array}{l}\text { Conflicts and trade- } \\
\text { offs in a river basin }\end{array}$ \\
\hline Target & $\begin{array}{l}\text { New Mexico resi- } \\
\text { dents }\end{array}$ & $\begin{array}{l}\text { Tarawa atoll resi- } \\
\text { dents and policy } \\
\text { makers }\end{array}$ & Teenage students & UK residents \\
\hline Data collection & Interviews & $\begin{array}{l}\text { Semi-automatic } \\
\text { software }\end{array}$ & N/A & NA/ \\
\hline Platform & Web and mobile & $\begin{array}{l}\text { PC supported board } \\
\text { game }\end{array}$ & Web & Web \\
\hline Technology & N/A & $\begin{array}{l}\text { VisualWorks and } \\
\text { CORMAS platform }\end{array}$ & Flash & Flash \\
\hline
\end{tabular}

Table 11: Summary of water games features. Games analyzed (Irrigania, Run the River, [74], SeGWADE, DropTheQuestion!).

\begin{tabular}{|c|c|c|c|c|c|}
\hline & Irrigania [73] & Run the river ${ }^{2}$ & [74] & SeGWADE [75] & $\begin{array}{l}\text { Drop The Question } \\
{[]}\end{array}$ \\
\hline Technology & $\begin{array}{l}\text { VisualBasic } \\
\text { ASP.NET }\end{array}$ & N/A & $\begin{array}{l}\text { Mixed (option card } \\
\text { selection and model } \\
\text { simulation) }\end{array}$ & HTML5 and WebGL & Java \\
\hline Roles & Farmer & Decision maker & Decision makers & $\begin{array}{l}\text { Water Distribution } \\
\text { Systems managers }\end{array}$ & Water expert \\
\hline Feedback & No feedback & In game alerts & $\begin{array}{l}\text { Model-derived } \\
\text { feedback }\end{array}$ & $\begin{array}{l}\text { Continuous and } \\
\text { instant feedback to } \\
\text { players }\end{array}$ & No feedback \\
\hline Mechanics & $\begin{array}{l}\text { turn-based strategy } \\
\text { game }\end{array}$ & Simulation & Model simulation & Model simulation & Trivia \\
\hline Issues & $\begin{array}{l}\text { Governance and } \\
\text { management of } \\
\text { common resources }\end{array}$ & $\begin{array}{l}\text { Balancing water use } \\
\text { between various } \\
\text { water consumers }\end{array}$ & River management & $\begin{array}{l}\text { Water Distribution } \\
\text { Systems design } \\
\text { decisions }\end{array}$ & General water culture \\
\hline Players & Single player & Single player & Teams & & Single player \\
\hline Focus & $\begin{array}{l}\text { Water sharing poli- } \\
\text { cies, water scarcity }\end{array}$ & $\begin{array}{l}\text { Water management } \\
\text { policies }\end{array}$ & $\begin{array}{l}\text { Water management } \\
\text { policies under multi- } \\
\text { ple perspectives }\end{array}$ & $\begin{array}{l}\text { Drinking Water } \\
\text { Distribution Systems }\end{array}$ & $\begin{array}{l}\text { Interesting facts on } \\
\text { water and water } \\
\text { consumption }\end{array}$ \\
\hline Target & Students & Kids & $\begin{array}{l}\text { Students, researchers. } \\
\text { and professionals }\end{array}$ & Students & Family \\
\hline Platform & Web & $\begin{array}{l}\text { Mobile phones and } \\
\text { tablets }\end{array}$ & $\mathrm{N} / \mathrm{A}$ & $\begin{array}{l}\text { Windows, Linux, } \\
\text { iOS and Android }\end{array}$ & $\begin{array}{l}\text { Android mobile } \\
\text { devices }\end{array}$ \\
\hline Data collection & Discussion in class & $\begin{array}{l}\text { Based on actual and } \\
\text { modelled historic } \\
\text { data }\end{array}$ & $\begin{array}{l}\text { Water system mod- } \\
\text { elled with Integrated } \\
\text { Assessment } \\
\text { Meta Model (IAMM) }\end{array}$ & $\begin{array}{l}\text { Feedback computed } \\
\text { with hydraulic simu- } \\
\text { lation engine based } \\
\text { on EPANET }\end{array}$ & N/A \\
\hline
\end{tabular}

In summary, findings from existing literature suggest that gamification strategies and games with a purpose can be applied in resource efficiency context with a good user acceptance and successful results in savings (as supported by empirical studies such as [68]). However, the success depends on many factors, most of them related with the design of the incentive models and game mechanics motivating the usage of the systems and the specific system functionalities offered.

The most important points and lessons from the literature include:

- Providing real time and historical information of the consumption is important, but the data is useless if the consumer cannot associate meaning to it, therefore informative measurement should go along with the real data (e.g. presenting cost in terms of money along with the consumption in cubic meters).

- Real word rewards and prizes are a good strategy to keep user engagement, but it is important to select them according to the type of consumers. Having various prizes with different options seems to be a good solution when the player population is diverse.

- Games are good influencers when trying to make changes in consumer behaviors, but permanent changes are difficult to achieve. The game mechanics have to be powerful enough to keep the user mind set, a good recommendation is to strongly relate the actions and points in the game with actions in the real world. 
- People are now aware of the problems related with resources and are willing to change their behavior, but constant, useful and interesting information about what to change and how to change it should be always available on demand and offered by the game.

- Designing systems that can successfully stimulate behavioural change requires a systematic modelling of the behavioural change process and its implementation through different types of incentives (virtual, physical, social) adapted to the characteristics of specific target user groups [69].

- Social interaction and competition are powerful engagers and influencers of behavior, they should be exploited but in some cases moderation might be required and evaluation should be made about the effort required in relation with the benefits.

Further discussion and examples of serious games for the water management field can be found in [75].

\section{Some experiences from the design and deployment of the SmartH2O system}

In this section we consider some of the main experiences from the design and deployment of the SmartH2O gamified system for behavioural change. In particular, we show how design guidelines for gamified consumption visualisations have informed the design of the SmartH2O system, suggesting their suitability to guide the design of such classes of applications. We also summarize some of the first evaluation results, with respect to user feedback, system acceptance and participation dynamics, as well as first encouraging results of observed reduction in water consumption in a small scale pilot.

\subsection{Design guidelines for visualisation and gamificationn in water saving applications}

Beyond leaning on findings from motivational and psychological theory in the design of the incentive model, the design of the SmartH2O system described in Section 3.1.4 also paid particular attention to effective use of visualisation and its integration with gamification elements for supporting behavioural change. Based on the literature review of consumption visualization and use of gamified elements for water and energy conservation (as structurally similar domains [70]), initial guidelines were formulated and supplemented with findings from the SmartH2O requirements analysis workshops to yield a set of design guidelines for water and energy saving applications (see Table $\mathrm{x}$ ).

Table 12: Design guidelines for water and energy saving applications (Micheel et al., 2015, p. 557f.)

\begin{tabular}{|c|c|c|}
\hline & \multicolumn{2}{|l|}{ Refined aspects from SmartH2O design cycle \& user workshops } \\
\hline & Present interactive layered visualization (simplest by default) & \begin{tabular}{|c|c|} 
c & Goals should be related to concrete actions users can perform \\
\end{tabular} \\
\hline & Use visual metaphors relating to user's consumption context & $\begin{array}{l}\text { d } \begin{array}{l}\text { Feedback on consumption should be action } \\
\text { saving tips embedded in the visualization }\end{array} \\
\end{array}$ \\
\hline \multirow[t]{4}{*}{ b } & Presen & \multirow{2}{*}{\begin{tabular}{|l|l|} 
e & Real rewards should engage even more pragmatic users \\
$\begin{array}{l}\text { Separate views for pragmatic \& hedonic users should be con- } \\
\text { sidered }\end{array}$
\end{tabular}} \\
\hline & $\begin{array}{l}\text { Overview of con } \\
\text { detailed informa } \\
\end{array}$ & \\
\hline & Units \& analogies should illustrate consumption \& savings & \multirow{2}{*}{\begin{tabular}{l|l|}
$\mathbf{f}$ & Common goals have the potential to bring e.g. neighbors closer \\
$\begin{array}{l}\text { Both are promising for different users embedded in the relevant } \\
\text { social context: in-group collaboration, intra-group competition }\end{array}$ \\
\end{tabular}} \\
\hline & $\begin{array}{l}\text { Showing consumption rather than smaller savings can rais } \\
\text { awareness }\end{array}$ & \\
\hline
\end{tabular}

Accordingly, the SmartH2O system incorporated different types of visualization linked with gamified elements (such as saving goals) described in Section 3.1.4. Most clearly, the application of the guidelines is reflected in the design of metaphor-based overview visualisation. In a first version it employed a speedometer metaphor, that showed daily and monthly consumption in comparison to one's average (Figure 13a), while in a second version, this was replaced with a water pipe metaphor (Figure 13b) to support more immediate cognitive mapping to the water topic and reinforce water awareness. The pipe metaphor formed the basis for integrating goal setting and gamified elements with the consumption visualisation, as can be seen from the yellow box in Figure 13b (e.g. setting self-set goals and receiving double points when reaching them, visual alerts about current consumption with respect to set goals, using swiming pool analogy to illustrate the meaning of the amount of saved water etc.). Similarly, while the bar chart overview visualisation (see Figure 13) supported more pragmatically oriented users and needs, the water pipe visualisation supported also hedonic aspects. Displaying the own consumption average and the average of the neighbourhood in the bar chart view all (Figure 13) supported social comparison. Linking achieved points to different type of collectable real 
rewards, addressed more pragmatic users for whom social comparison or symbolic awards (such as badges) weren't enough to motivate action.

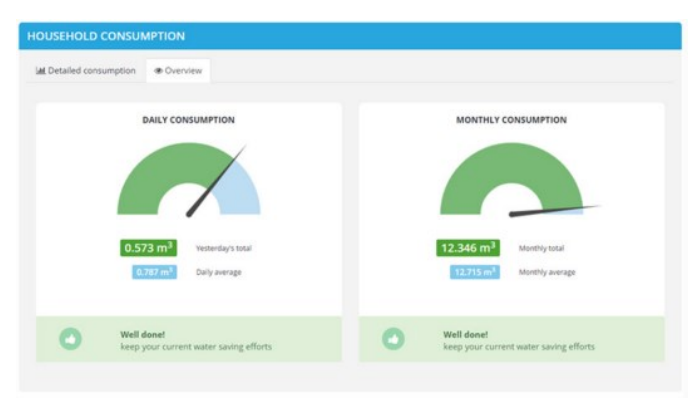

a)
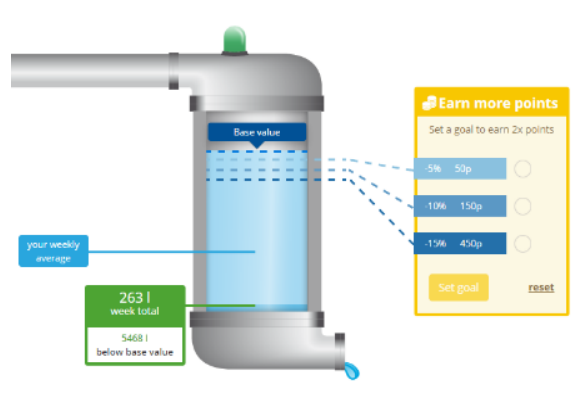

b)

Figure 13: Metaphoric visualisations: a) speedometer-based display, b) water pipe metaphor

\subsection{Evaluating user responses and first effects on water consumption}

The results of preliminary evaluation of the SmartH2O system in the first pilot in the municipality of Tegna (Switzerland), although reflecting a small initial test base confirmed the suitability of such a design, suggesting that the identified design guidelines are suitable for informing the design of such systems. There, the system has been deployed in two versions: as a basic portal implementing only the "pragmatic" elements, such as the interactive water consumption visualisation and the water saving tips, and the gamified portal adding goal setting and the full spectrum of gamified incentives and rewards. After a 4 months of basic portal trial with 40 users (households) user feedback collected with an online questionnaire ( $n=15 / 37,5 \%$ response rate) revealed that most users found that the system made water conservation more interesting (11/15 users) with half of them finding it fun to use (7/15), indicating that even a non-gamified system incentivizes use (for more details see [69]). In particular, most respondents found the interactive water consumption chart easy to use (9 / 15 users) and almost all respondents (14 / 15 users) agreed that from the chart and the overview visualisations they could understand how much water their household consumed over time [69]. The perceived usefulness of the main design elements (the water consumption chart ( 8 / 15 users), consumption overview ( 7 / 15 users) and water saving tips ( 9 / 15 users)) was also relatively positively rated, and for all these three features most users also stated that they made them think about water conservation more often (11/15 users). Even though tentative in nature, and only based on a first simple version of the visualisations (bar chart view and speedometer metaphor), the results suggest that the designed visualisations were capable of incentivizing users to reflect on their consumption.

Following this initial assessment of user acceptance (based on the model by [71]) the evaluation of the gamified portal through the analysis of user activity was also performed. This system version also included the new consumption visualisation using a pipe metaphor. To gain first insights into incentive dynamics on the gamified portal, user activity logs in the Swiss case were analysed study (Dec'15-Feb'16). After its launch in December 2015, little activity occurred on the basic portal compared to the gamified portal, which exhibited almost twice as many logins as the former [69]. This suggests that the gamification features prompted more interest, with activity peaking after a mail campaign to current users. An inspection of individual elements revealed that the consumption chart has been viewed and interacted with the most. Other key elements like the leaderboard, achievements and actions panels were also accessed more than once by over half of the users and almost all users collected badges. These indicators suggest that the incentive model is capable of motivating users to access and use it, and thus to engage with water consumption information. The overall results suggest that even with a small user community and not a very long period for the incentive model to yield effects, the system was able to motivate different participation dynamics (ibid.). Even though these observed dynamics need to be assessed in more detail in the large scale pilot, such differences in responses to the incentive model highlight the importance of a holistic approach that comprises different motivational affordances to support the behavioural change process for all users (ibid.).

Consumption effects were measured with respect to a historical yearly baseline for each user. We have observed that users with a low and medium consumption volume achieve the highest reductions (see [72] for details). After discounting the possible effect of the winter season on lower consumption (to an upper bound 
of $25-30 \%$ ), a water consumption reduction of $3.4-8.4 \%$ that could be attributed to the use of the portal remained. This first encouraging result needs to be validated once detailed consumption logs will be made available for the whole year, enabling us to make a meaningful comparison with the baseline.

Finally, some of the other lessons learned in the design, deployment and evaluation of the SmartH2O system include:

- Gamification in combination with physical rewards can be a good way to strengthen the incentive induced by consumption feedback, as physical rewards have proven to be capable of engaging users who are not necessarily motivated by playful elements and associated virtual or social rewards. Business factors such as the available budget and the image the utility seeks to communicate to its customers shape the reward model, in terms of the type of rewards, the number of available rewards, and the user actions in the applications that make a user eligible for a reward.

- Whereas in traditional approaches the collection of user data requires substantial effort, in SmartH2O the gamified incentive model has proven to be capable of eliciting user-generated data about the household composition, water consuming appliances, presence of a garden or balcony and other factors that determine water consumption levels. These data allow utilities to model the water demand beyond what can be inferred from aggregated (smart metered) readings by clustering consumers based on socio-psychographic features and/or disaggregating consumption to the level of water consumption appliances [73], [74].

- Experiences from SmartH2O and other projects [15] [75] strongly suggest that the sustainability of effects on water consumption behavior cannot be taken for granted. Rather, utilities must be aware of the fact that relapse to "old" consumption behavior can and will occur. A significant share of water consumption behavior is habitual, which is notoriously difficult to change (e.g. [76]), requiring utilities to commit to a long-term implementation of behavioral change interventions and to allocate their required resources.

Such experiences from the SmartH2O project can support water utilities (or researchers) who intend to develop similar applications, as part of their water demand management strategy and as a way of developing new kinds of water consumption information services for their customers.

\section{Conclusions}

Gamification mechanisms appear to be promising and acceptable tools for incentivizing pro-environmental attitudes and promoting water conservation habits in urban contexts. Following this potential, several EUfunded projects focused on assessing the effectiveness of gamified tools to support water demand-side management, integrated with ICT solutions, as well as advanced metering infrastructure. In this chapter, we reviewed the most relevant experiences from state-of-the art projects, and presented the SmartH2O platform, a web-based gamified user portal that we developed as part of the EU-funded SmartH2O project and implemented in two real case studies, in Switzerland and Spain.

Our comparative analysis, as well as the preliminary results we obtained from real-world testing, suggest a few general take-home messages for the future exploitation of gamification mechanisms to design water demand management strategies. In particular, the number of experiences developing gamified approaches to water conservation and other environmental purposes in Europe and worldwide values such tools as alternatives/complements to more traditional top-down interventions (e.g., water use restrictions or mandatory retrofitting interventions). Besides, gamified applications do not purely constitute single-direction communication tools for giving behavioural suggestions to users. Rather, they can easily include interactive modules incentivizing users to provide data (e.g., demographics), which would be more difficult to collect and update with traditional surveys or una tantum data gathering campaigns. Therefore, their value to support user modelling and customized demand management activities is increased.

Yet, rigorous studies comparing exhaustively, with a complete set of quantitative and qualitative performance metrics, the state-of-the-art gamified methods to enhance awareness and behavioural change toward environmental issues do not exist. Therefore, findings and consideration on the effectiveness of 
such methods should be related to specific case-studies and applications so far, and a generalization and integration effort is required.

Finally, the preliminary results of the SmartH2O project support the effectiveness of gamified approaches to pursue water savings, at least in the short-term, and we were able to draw some recommendations for the future development of such approaches (e.g., combining gamified mechanisms with real, physical rewards). Yet, their long-term effectiveness has not generally been assessed so far, as well as ways to keep it high and avoid the rebound effect. Therefore, future research and system implementations, involving researchers, utilities, and water consumers, should commit to a long-term design and testing of behavioural change interventions, possibly considering city-scale samples of heterogeneous users and designing alternative customized demand-side management actions.

\section{Bibliography}

[1] P. Gerland, A. E. Raftery, H. Ševčíková, N. Li, D. Gu, T. Spoorenberg, L. Alkema, B. K. Fosdick, J. Chunn, N. Lalic, G. Bay, T. Buettner, G. K. Heilig y J. Wilmoth, «World population stabilization unlikely this century,» Science, vol. 346, no 6206, pp. 234-237, 2014.

[2] UNDESA, «World Urbanization Prospects: The 2014 Revision,» 2014.

[3] R. I. McDonald, P. Green, D. Balk, B. M. Fekete, C. Revenga, M. Todd y M. Montgomery, «Urban growth, climate change, and freshwater availability,» Proceedings of the National Academy of Sciences, vol. 08, $\mathrm{n}^{\circ}$ 15, pp. 6312-6317, 2011.

[4] P. H. Gleick y M. Palaniappan, «Peak water limits to freshwater withdrawal and use,» Proceedings of the National Academy of Sciences, vol. 107, $\mathrm{n}^{\circ}$ 25, pp. 11155-11162, 2010.

[5] C. D. Beal, T. R. Gurung y R. A. Stewart, «Demand-side management for supply-side efficiency: Modeling tailored strategies for reducing peak residential water demand,» Sustainable Production and Consumption, vol. 6, pp. 1-11, 2016.

[6] A. Cominola, M. Giuliani, D. Piga, A. Castelletti and A. E. Rizzoli, "Benefits and challenges of using smart meters for advancing residential water demand modeling and management: A review," Environmental Modelling and Software, vol. 72, pp. 198-214, 2015.

[7] R. Cahill y J. Lund, «Residential water conservation in Australia and California,» Journal of Water Resources Planning and Management, vol. 139, $\mathrm{n}^{\mathrm{o}}$ 1, pp. 117-121, 2012.

[8] R. M. Willis, R. A. Stewart, K. Panuwatwanich, S. Jones y A. Kyriakides, «Alarming visual display monitors affecting shower end use water and energy conservation in Australian residential households,» Resources, Conservation and Recycling, vol. 54, $\mathrm{n}^{\circ}$ 12, pp. 1117-1127, 2010.

[9] J. Froehlich, L. Findlater, M. Ostergren, S. Ramanathan, J. Peterson, I. Wragg, E. Larson, F. Fu, M. Bai, S. Patel y J. Landay, «The design and evaluation of prototype eco-feedback displays for fixture-level water usage data.,» de Proceedings of the SIGCHI conference on human factors in computing systems, 2012.

[10] V. Desley, B. Laurie y M. Peter, «The effectiveness of energy feedback for conservation and peak demand: a literature review,» Open Journal of Energy Efficiency, 2013.

[11] A. L. Sønderlund, J. R. Smith, C. Hutton y Z. Kapelan, «Using smart meters for household water consumption feedback: knowns and unknowns.,» Procedia Engineering, vol. 89, pp. 990-997, 2014.

[12] P. W. Mayer, W. B. DeOreo, E. M. Opitz, J. C. Kiefer, W. Y. Davis, B. Dziegielewski and J. O. Nelson, "Residential end Uses of Water," AWWA Research Foundation and American Water Works Association, 1999.

[13] R. Cardell-Oliver, «Water use signature patterns for analyzing household consumption using medium resolution meter data,» Water Resources Research, vol. 49, n 12, pp. 8589-8599, 2013.

[14] S. Russell y K. Fielding, «Water demand management research: A psychological perspective,» Water Resources Research, vol. 46, $\mathrm{n}^{\circ}$ 5, 2010.

[15] K. S. Fielding, A. Spinks, S. Russell, R. McCrea, R. Stewart and J. Gardner, "An experimental test of voluntary strategies to promote urban water demand management," Journal of Environmental Management, vol. 114, p. 343$351,2013$.

[16] J. Schell, The Art of Game Design: A book of lenses, CRC Press, 2008.

[17] D. Börner, M. Kalz, S. Ternier y M. Specht, «Pervasive interventions to increase pro-environmental awareness, 
consciousness, and learning at the workplace,» de European Conference on Technology Enhanced Learning, 2013.

[18] D. Charitos, I. Theona, C. Rizopoulos, K. Diamantaki y V. Tsetsos, «Enhancing citizens' environmental awareness through the use of a mobile and pervasive urban computing system supporting smart transportation,» de Interactive Mobile Communication Technologies and Learning (IMCL), 2014 International Conference, 2014.

[19] A. L. Negruşa, V. Toader, A. Sofică, M. F. Tutunea y R. V. Rus, «Exploring gamification techniques and applications for sustainable tourism,» Sustainability, vol. 7, nº 8, pp. 11160-11189, 2015.

[20] K. Madani, T. W. Pierce y A. Mirchi, «Serious games on environmental management,» Sustainable Cities and Society, vol. 29, pp. 1-11, 2017.

[21] A. Rizzoli, A. Castelletti, A. Cominola, P. Fraternali, A. Diniz dos Santos, B. Storni, R. Wissmann-Alves, M. Bertocchi, J. Novak and I. Micheel, "The SmartH2O project and the role of social computing in promoting efficient residential water use: a first analysis," in Proceedings of the 7th International Congress on Environmental Modelling and Software, 2014.

[22] T. Boyle, D. Giurco, P. Mukheibir, A. Liu, C. Moy, S. White and R. Stewart, "Intelligent metering for urban water: a review," Water, vol. 5, pp. 1052-1081, 2013.

[23] C. Beal, R. Stewart, D. Giurco and K. Panuwatwanich, "Intelligent metering for urban water planning and management," in Water efficiency in buildings: theory and practice, West Sussex, U.K., Adeyeye, K (Ed)., 2014.

[24] V. Sempere-Paya, D. Todolí-Ferrandis y S. Santoja-Climent, «ICT as an enabler to smart water management,» de Smart sensor for real-time water quality monitoring, London, UK. , Mukhopadhyay, S. C. \& Mason, A. (Eds.) Springer, 2013.

[25] T. Britton, R. Stewart and K. O'Halloran, "Smart metering: enabler for rapid and effective post meter leakage identification and water loos management," Journal of Cleaner Production, vol. 54, pp. 166-176, 2013.

[26] Houses of Parliament, "Smart metering of energy and water: no. 417," The parliamentary Office of Science and Technology, London, U.K..

[27] Oracle Utilities, "Smart Metering for water utilities: White Paper," 2009. [Online]. Available: https://www.oracle.com/industries/utilities/index.html.

[28] A. Cuzzocrea, I.-Y. Song and K. C. Davis, "Analytics over Large-Scale Multidimensional Data: The Big Data Revolution!," in Proceedings of the ACM 14th international workshop on Data Warehousing and OLAP, Glasgow, Scotland, UK, 2011.

[29] A. Zoha, A. Gluhak, M. A. Imran and S. Rajasegarar, "Non-intrusive load monitoring approaches for disaggregated energy sensing: A survey," Sensors, vol. 12, no. 12, p. 16838-16866, 2012.

[30] A. Cominola, A. Moro, L. Riva, M. Giuliani and A. Castelletti, "Profiling residential water users' routines by eigenbehavior modelling," in 8th International Congress on Environmental Modelling and Software, Tolouse, France, 2016.

[31] B. J. Fogg, Persuasive Technology: Using Computers to Change What We Think and Do, San Francisco: Morgan Kaufmann Publishers, 2003.

[32] S. Card, J. Mackinlay and B. Shneiderman, Readings in Information Visualization. Using Vision to Think, San Francisco: Morgan Kaufmann Publishers, 1999.

[33] A. V. Pandey, A. Manivannan, O. Nov, M. L. Satterthwaite and E. Bertini, "The Persuasive Power of Data Visualization," New York University Public Law and Legal Theory Working Papers, paper n. 474, 2014.

[34] Tactical technology collective, "Visualising Information for Advocacy," 2013. [Online]. Available: https://visualisingadvocacy.org/.

[35] S. Deterding, R. Khaled, L. E. Nacke and D. Dixon, "Gamification: Toward a definition," in CHI 2011: Workshop Gamification: Using Game Design Elements in Non-Game Contexts, Vancouver, BC, Canada, 2011.

[36] F. Groh, «Gamification: State of the Art Definition and Utilization,» Research Trends in Media Informatics, p. 3946, 2012.

[37] J. Hamari, J. Koivisto and H. Sarsa, "Does Gamification Work? A Literature Review of Empirical Studies on Gamification," in Annual Hawaii International Conference on System Sciences, 2014.

[38] K. Ling, G. Beenen, P. Ludford, X. Wang, K. Chang, X. Li, D. Cosley, D. Frankowski, L. Terveen, A. M. Rashid, P. Resnick and R. Kraut, "Using Social Psychology to Motivate Contributions to Online Communities," Journal of Computer-Mediated Communication, vol. 10, no. 4, 2005.

[39] R. Bartle, "Hearts, clubs, diamonds, spades: Players who suit muds," 1996. [Online]. Available: http://mud. co.uk/richard/hcds.htm.

[40] K. Kyatric, "Bartle's Taxonomy of Player Types (And Why It Doesn't Apply to Everything)," 2013. [Online]. Available: http://gamedevelopment.tutsplus.com/.

[41] "Urban Water," [Online]. Available: http://urbanwater-ict.eu/. 
[42] Urban Water, "Document of Work (DOW)," 01 July 2015. [Online]. Available: http://urbanwater-ict.eu/wpcontent/uploads/2015/12/DOW-UrbanWater-318602-2015-07-01.pdf.

[43] P. Avila, A. Cisneros, A. Rodriguez and L. Tena, "UrbanWater D6.2: UrbanWater platform architecture design," 2015.

[44] A. Broussel, "UrbanWater D6.4: UrbanWater Platform Prototype," 2015.

[45] J. Nielsen, A. Rodriguez, A. Broussel, S. Flake, G. Sinne and P. Avila, "UrbanWater D5.6: Game solution for customer empowerment using water consumption data," 2015.

[46] "WatERP," [Online]. Available: http://www.waterp-fp7.eu/.

[47] C. Chomat, "WatERP D 1. 2: Generic functional model for water supply and usage data," 2013.

[48] "Waternomics," [Online]. Available: http://waternomics.eu/.

[49] S. Smit, Waternomics: Key Ideas, brochure \& poster, 2015.

[50] D. Coakley, W. Derguech, S. Hasan, C. Kouroupetroglou, Y. Lu, J. Mink, D. Perfido, Hassan and U. U. I., "Waternomics: D1.3 System Architecture and KPIs," 2015.

[51] C. Kouroupetroglou, J. van Slooten, N. Kasfikis, W. Derguech, E. Curry, S. Hasan, S. Smit and D. Perfido, "Waternomics: WATERNOMICS Apps," 2016.

[52] «Water Footprint Network,» [En línea]. Available: http://waterfootprint.org/.

[53] "SmartH2O: an European Project on Water Sustainability," [Online]. Available: http://www.smarth2o-fp7.eu/.

[54] H. Oinas-Kukkonen, "A foundation for the study of behavior change support systems," Personal Ubiquitous Computing, vol. 17, no. 6, pp. 1223-1235, 2013.

[55] M. Nachreiner, B. Mack, E. Matthies y K. Tampe-Mai, «An analysis of smart metering information systems: A psychological model of self-regulated behavioural change,» Energy Research and Social Science, vol. 9, p. 85-97, 2015.

[56] K. S. Fielding, S. Russell, A. Spinks y A. Mankad, «Determinants of household water conservation: The role of demographic, infrastructure, behavior, and psychosocial variables,» Water Resources Research, vol. 48, $\mathrm{n}^{\circ}$ 10, 2012.

[57] "IBM Intelligent Water," [Online]. Available: http://www-03.ibm.com/software/products/en/intelligentwater.

[58] "SimuTech Group," [Online]. Available: http://www.simutechgroup.com/.

[59] "Oracle Utilities," [Online]. Available: http://www.oracle.com/industries/utilities.

[60] G.Peschiera, J. E. Taylor and J. A. Siegel, "Response-relapse patterns of building occupant electricity consumption following exposure to personal, contextualized and occupant peer network utilization data," Energy and Buildings, vol. 42, no. 8, p. 1329-1336, 2010.

[61] I. Bogost, Persuasive games: The expressive power of videogames, MIT Press, 2007.

[62] B. J. Fogg, Persuasive Technology: Using Computers to Change What We Think and Do, San Francisco: Morgan Kaufmann Publishers, 2003.

[63] T. Hirsch, "Water wars: designing a civic game about water scarcity," in Proceedings of the 8th ACM Conference on Designing Interactive Systems, pp. 340-343, 2010.

[64] A. Dray, P. Perez, C. LePage, P. D’Aquino and I. White, Companion modelling approach: the atollgame experience in tarawa atoll (republic of kiribati)., 2005.

[65] A. Science, "Catchment detox," 2014. [Online]. Available: http://www.abc.net.au/science/catchmentdetox/.

[66] G. Rebolledo-Mendez, K. Avramides, S. d. Freitas and K. Memarzia, "Societal impact of a serious game on raising public awareness: the case of floodsim.," in Proceedings of the 2009 ACM SIGGRAPH Symposium on Video Games, pp.15-22, 2009.

[67] "Acqua republica," [Online]. Available: http://aquarepublica.com/.

[68] C. Rottondi, A. Facchini and A. Rizzoli, "An Agent Based Framework for Residential Water Usage Modelling under Social Stimuli," in 2016, Toulouse, France, 8th International Congress on Environmental Modelling and Software .

[69] J. Novak, M. Melenhorst, I. Micheel, C. Pasini, P. Fraternali and A. Rizzoli, "Behaviour change and incentive modelling for water saving: first results from the SH2O project," in Proceedings of 8th International Congress on Environmental Modelling and Software, in Toulouse, France, 2016.

[70] I. Micheel, J. Novak, P. Fraternali, G. Baroffo, A. Castelletti and A. E. Rizzoli, "Visualizing \& gamifying water \& energy consumption for behavior change," in Workshop: Fostering Smart Energy Applications pp. 555-564, 2015.

[71] V. Venkatesh, M. G. Morris, D. G. B. and F. D. Davis, "User Acceptance of Information Technology: Toward a Unified View," MIS Quarterly, vol. 27, no. 3, pp. 425-478, 2003.

[72] M. Bertocchi, M. Melenhorst, I. Micheel, J. Novak, L. Caldararu, C. Rottondi, C. Pasini, P. Fraternali, R. Marzano, 
C. Rouge, G. J. C., N. Bakkalian, M. Velázquez and A. Rizzoli, "Deliverable D7.2 WP7," The SmartH2O project, a European Project on Water Sustainability, 2016.

[73] R. M. Willis, R. A. Stewart, D. P. Giurco, M. Reza Talebpour and A. Mousavinejad, "End use water consumption in households: impact of socio-demographic factors and efficient devices," Journal of Cleaner Production, vol. 60, no. 1, pp. 107-115, 2013.

[74] A. A. Makki, R. A. Stewart, C. D. Beal and K. Panuwatwanich, "Novel bottom-up urban water demand forecasting model: Revealing the determinants, drivers and predictors of residential indoor end-use consumption," Resources, Conservation and Recycling, vol. 95, pp. 15-37, 2015.

[75] P. W. Schultz, A. Messina, G. Tronu, E. F. Limas, R. Gupta and M. Estrada, "Personalized Normative Feedback and the Moderating Role of Personal Norms A Field Experiment to Reduce Residential Water Consumption," Environment and Behavior, vol. 48, no. 5, pp. 686-710, 2014.

[76] U. Dahlstrand y A. Biel, « Pro-Environmental Habits: Propensity Levels in Behavioral Change,» Journal of Applied Social Psychology, vol. 27, p. 588-601, 1997.

[77] N. Nakicenovic and R. Swart, "Special Report on Emission Scenarios," Intergovernmental Panel on Climate Change (IPCC), Cambridge University Press, Cambridge, UK., 2000.

[78] S. Solomon, D. Qin, M. Manning, Z. Chen, M. Marquis, K. Averyt, M. Tignor and H. Miller, "Climate change 2007: The physical science basis. Contribution of working group II to the Fourth Assessment Report of the Intergovernmental Panel on Climate Change," Intergovernmental Panel on Climate Change (IPCC), Cambridge University Press, New York., 2007.

[79] M. Parry, O. Canziani, J. Palutikof, P. v. d. Linden and C. Hansson, "Climate change 2007: Impacts, adaptation and vulnerability. Contribution of working group II to the Fourth Assessment Report of the Intergovernmental Panel on Climate Change," Intergovernmental Panel on Climate Change (IPCC), Cambridge University Press, New York., 2007.

[80] O. Edenhofer, R. Pichs-Madruga, Y. Sokona, E. Farahani, S. Kadner, K. Seyboth, A. Adler, I. Baum, S. Brunner, P. Eickemeier, B. Kriemann, J. Savolainen, S. Schlömer, C. v. Stechow, T. Zwickel and J. Minx, "Climate change 2014: Mitigation of Climate Change. Contribution of working group III to the Fifth Assessment Report of the Intergovernmental Panel on Climate Change," Cambridge University Press, Cambridge, United Kingdom and New York, NY, USA., 2014.

[81] N. Johnson, C. Revenga and J.Echeverria, "Managing Water for People and Nature," Science, vol. 292, pp. 1071$1072,2001$.

[82] Global Water Partnership Technical Advisory Committee, "Integrated Water Resources Management," TAC Background Papers No. 4., 2000.

[83] [Online]. Available: http://www.gwp.org/.

[84] K. Conradin, "Integrated Water Resources Management (IWRM), Sustainable Sanitation and Water Management," [Online]. Available: http://www.sswm.info/category/concept/iwrm.

[85] S. M. Easterbrook, "Climate Change: A Software Grand Challenge," in FSE/SDP Workshop on the Future of Software Engineering Research, Santa Fe, 2010.

[86] Z. Wang, H. Song, D. W. Watkins, K. G. Ong, P. Xue, Q. Yang and X. Shi, "Cyber-physical systems for water sustainability: challenges and opportunities," IEEE Communications Magazine, vol. 53, no. 5, pp. 216--222, 2015.

[87] M. Ward, Dirección, Smart meters can be hacked to cut power bills. [Película]. London, U.K: BBC, 2014.

[88] J. Harou, P. Garrone, A. Rizzoli, A. Maziotis, A. Castelletti, P. Fraternali, J. Novak, R. Wissmann-Alves and P. Ceschi, "Smart metering, water pricing and social media to stimulate residential water efficiency: Opportunities for the smarth2o project," Procedia Engineering, vol. 89, pp. 1037-1043, 2014. 